\title{
AÇÕES EXTENSIONISTAS PARA O CONTROLE SOCIAL DOS RECURSOS PÚBLICOS SOCIOASSISTENCIAIS EM ALIMENTAÇÃO
}

Hellen Priscilla das Virgens Santana - hellenpriscillavs@gmail.com

Felipe da Cruz Rocha - felipicruz123@gmail.com

Glaucia Maria da Silva Oliveira - gal.mb23@hotmail.com

PET/MEC Engenharias

Universidade Estadual de Feira de Santana, Colegiado de Agronomia

Avenida Transnordestina s/n, Módulo 1

Pablo Rodrigo Fica Piras - pafipi@uefs.br

PET/MEC Engenharias

Universidade Estadual de Feira de Santana, Departamento de Tecnologia

Avenida Transnordestina s/n, Módulo 3

44036-900 - Feira de Santana - Bahia

Resumo: Em tempos em que se estima que o Brasil está retornando ao mapa da fome $F A O$, o presente trabalho identifica a natureza multidimensional do tema, apresenta a análise de dados e constatações do PET Engenharias em torno ao Programa de Aquisição de Alimentos - PAA Compra Direta ("renda para quem produz, comida para quem precisa") e analisa a eficácia desta política pública com recursos federais. Para tanto, o Grupo participou no Conselho Municipal de Segurança Alimentar - CONSEA da cidade, acedeu cadastramentos tanto de produtores (570 entidades) quanto de recebedores dos alimentos (112 entidades) $e$ realizou visitas aos produtores familiares de sete locais, nos distritos do Norte do Município. Transformados compulsoriamente em ouvintes no Conselho, os membros do Grupo realizaram algumas constatações: 1) as aquisições de alimentos eram realizadas intempestivamente, impedindo o planejamento dos fornecedores e lesionando o propósito da sustentação econômica dos agricultores; 2) o cadastramento era feito com critérios proselitistas, condicionando a permanência a um comportamento de troca de favores; 3) o gestor não atua na solução do problema hídrico; 4) as propriedades são de tamanho inferior ao necessário para a atividade agrícola sustentada; 5) o CONSEA atua apenas como necessidade formal local para receber beneficios federais e alija a participação de representantes legítimos; em soma 6) dificulta, praticamente impede, o controle social e conculca a eficácia das políticas públicas relacionadas com alimentação.

Palavras-chave: Políticas públicas. Soberania alimentar e nutricional. CONSEA municipal. Programa de Aquisição de Alimentos - PAA. 


\section{Evento On-line}

\section{INTRODUÇÃO}

Em 15 de setembro de 2006, publica-se a Lei Orgânica de Segurança Alimentar e Nutricional (LOSAN), que determina uma estrutura composta pela Conferência Nacional de Segurança Alimentar, o Conselho Nacional de Segurança Alimentar e Nutricional (CONSEA) e a Câmara Interministerial de Segurança Alimentar e Nutricional (CAISAN) (BRASIL, 2006; Castro, 2019). Treze anos depois, no dia 24 de setembro de 2019, na Câmara Federal, 299 deputados federais apoiaram, com apenas 162 votos contrários, o veto presidencial à recriação do CONSEA, que tinha sido extinto em 01 de janeiro desse ano. Tratava-se de um espaço qualificado que permitia a participação da sociedade civil na discussão e desenho das políticas públicas. Houve mobilizações massivas nas grandes cidades e há um certo consenso em que este desaparecimento constitui um retrocesso governamental na garantia do DHAA (Direito Humano à Alimentação Adequada). Atendendo ao conjunto de instrumentos que essa iniciativa criou no país (Política e o Plano Nacional de Segurança Alimentar e Nutricional; Programas de Convivência com o Semiárido; Política Nacional de Agroecologia e Produção Orgânica; Plano Safra da Agricultura Familiar; Programa de Aquisição de Alimentos; Programa Nacional de Alimentação Escolar; Guia Alimentar da População Brasileira), sendo e orientando políticas públicas, o Brasil chegou em 2014 a estar fora do mapa da fome mundial da FAO, uma referência que se usa para afirmar que, pelo menos, $5 \%$ da população está em insegurança alimentar por falta de acesso, fortalecendo organizações da sociedade civil.

Como outros objetos de análise e reflexão em torno dos fenômenos sociais, a abordagem da segurança alimentar e nutricional - SAN deve ser multidimensional, identificando e articulando fatores causadores e possíveis soluções.

O presente trabalho descreve as ações do PET Engenharias no Controle Social realizado nas políticas de combate à insegurança alimentar em Feira de Santana, analisando os conceitos de Políticas Públicas e Controle Social Democrático vis-à-vis o conjunto de Ações Extensionistas desenvolvidas pelo PET Engenharias, em particular relacionadas com a Segurança Alimentar e Nutricional, através do PAA.

\section{As Políticas Públicas e o Controle Social Democrático}

A análise do programa começa pela a própria definição de política pública e do cumprimento do papel do Estado para efetivar os direitos primordiais de um cidadão. Aliado a isso, entende-se que a intervenção social é essencial para a garantia da efetividade desse programa, ou seja, o controle social por parte sociedade civil.

\subsection{Políticas públicas}

Tendo foco na sua efetividade, a avaliação de uma política pública precisa de um entendimento do papel do Estado para com a sociedade civil, incluindo atribuições de 
programas e políticas como a utilizada como objeto de estudo no presente trabalho. Para Höfling (2001), entende-se como política pública:

“(...) ações que determinam o padrão de proteção social implementado pelo Estado, voltadas, em princípio, para a redistribuição dos benefícios sociais visando a diminuição das desigualdades estruturais produzidas pelo desenvolvimento socioeconômico" (HÖFLING, 2001, p.31)

Sendo assim, uma política pública deve ser aplicada com base na solução das dificuldades e/ou problemas que são enfrentados na sociedade, havendo, imprescindivelmente, garantia da participação direta da população na construção e execução da política, até mesmo em processos de caráter seletivo. Isso porque, quem melhor entende de suas deficiências, desigualdades e demandas é a população atingida por tais mazelas, que deve ser mantida como protagonista no funcionamento de ações afirmativas dessa natureza.

A intervenção do Estado não deve ser reduzida apenas a categorias burocráticas de uma relação "civil-estatal", senão que deve ser entendida como fruto das lutas populares do século XIX, surgidas como remediações a conflitos entre capital e trabalho, logo nos primórdios das revoluções industriais (HÖFLING, 2001). Essa perspectiva escancara o dever de se manter a prioridade das necessidades das populações assistidas, com base em suas próprias manifestações de atribuições, necessidades e demandas, em contraponto aos interesses de grupos sociais privilegiados e detentores de poder econômico.

“(...) O processo de definição de políticas públicas para uma sociedade reflete os conflitos de interesses, os arranjos feitos nas esferas de poder que perpassam as instituições do Estado e da sociedade como um todo. (HÖFLING, 2001, p.38)

Com base nesse panorama, é possível atestar que a dinâmica econômica predatória e as relações de poder presentes nas raízes históricas brasileiras impedem que as necessidades dos indivíduos-alvo das políticas compensatórias sejam efetivamente sanadas, o que comprometem a palpabilidade de tais ações. Deve ter presente o projeto de poder que vigora na sociedade e como esse projeto resolve os conflitos nas relações sociais e suas desigualdades. Isso diz respeito também à fatores culturais, ou seja, condições sociais que estabelecem a forma como a sociedade civil enxerga as desigualdades acometidas por uma ou mais parcelas e de que forma absorvem as reivindicações que lhes são atribuídas. Essas condições determinam poder organizacional e de articulação dos grupos que precisam de mobilização e articulação para estabelecer reivindicações para a conquista, não só de serviços, mas para o usufruto de direitos primordiais para o exercício da cidadania.

\subsection{Controle social democrático}

A concepção de controle social surge a partir de 1980, inserida em um contexto de luta dos movimentos sociais pela redemocratização do Estado brasileiro. Segundo Calvi (2008), a 
partir dessa década, o termo passou a ser utilizado pelos movimentos sociais e demais instituições da sociedade civil para reivindicar a possibilidade de participação nos espaços de decisão referentes às políticas públicas. Portanto, o controle social é a integração da sociedade civil organizada na administração pública, com o objetivo de promover a participação, acompanhamento, proposição, elaboração, fiscalização e implantação das políticas públicas. O desenvolvimento do controle social compõe uma das diretrizes da Lei 12.527/2011, conhecida como Lei de Acesso à informação-LAI, que, além de garantir o direito de acesso às informações do poder público, permite a participação da sociedade na administração pública, a fim de assegurar a manutenção das políticas socioassistenciais, que devem estar a serviço da sociedade.

Os sujeitos deste controle social podem ser diversos, pois são também heterogêneos os setores da sociedade civil que eles vão representar. Em geral são entidades que agrupam populações que de alguma forma dialogam com a política pública em questão. Em uma posição privilegiada para isso estão os grupos que realizam ações extensionistas, em convergência com o próprio conceito da Extensão Universitária:

“(...) A Extensão é uma via de mão-dupla, com trânsito assegurado à comunidade acadêmica, que encontrará, na sociedade, a oportunidade de elaboração da práxis de um conhecimento acadêmico". (FORPROEX, 2012).

Trata-se de um campo em que naturalmente se enfrentam problemáticas, e cabe aprofundar na utilização de dados e documentos, investigando as dinâmicas de causa e efeito, procurando compreender as ações de controle social sobre as políticas públicas.

\section{Ações eXtensionistas}

$\mathrm{Na}$ atualidade, a perspectiva social sobre a universidade pública brasileira é de que ela se configure enquanto um espaço institucional, que possui função educacional e é responsável pela produção e disseminação do conhecimento, mantendo uma atitude crítica e reflexiva. $\mathrm{O}$ "fazer universitário" se materializa através da indissociabilidade entre o ensino, a pesquisa e a extensão, como consta no artigo 207 da Constituição Brasileira (1988). Este tripé contribui para um "fazer universitário" ético, autônomo e direcionado para uma formação sensível às problemáticas apresentadas pela sociedade em que está inserida. A ação extensionista corresponde também, mas não somente, a uma tentativa de devolução por parte da universidade do investimento recebido da sociedade. Portanto, a universidade deve manter uma relação constante com a comunidade na qual está inserida e ser gerida como um bem público, que deve estar a serviço da população brasileira.

Compreende-se como fundamental a realização de levantamentos das demandas apresentadas e, a partir disso, pensar e construir alternativas apropriadas de resposta. Neste particular, nos seus nove anos de trajetória, o grupo PET Engenharias-UEFS tem mantido como um dos seus focos a "Segurança Alimentar de comunidades de agricultura familiar do 
semiárido baiano", considerando que naturalmente pertencem ao este escopo de atuação tanto a introdução de tecnologia para possibilitar a geração de renda dos agricultores familiares quanto a adequada execução das políticas públicas vinculadas ao fornecimento de alimento às pessoas em situação de vulnerabilidade alimentar e nutricional. Por este motivo, o Grupo realiza ações extensionistas com este foco, em particular a de participação nas instâncias de controle social do Programa de Aquisição de Alimentos - PAA, um programa que recebe recursos federais e é gerido pela administração pública municipal.

\section{Segurança alimentar e nutricional através do paA}

A mitigação das desigualdades no acesso à alimentação e, em outra face, o acesso ao mercado pela agricultura familiar tem, em programas como PAA (Programa de Aquisição de Alimentos), uma das suas manifestações concretas mais difundidas. No período estudado, o PAA possuía três modalidades: Compra Direta da Agricultura Familiar - CDAF, Compra da Agricultura Familiar com Doação Simultânea - CPR-Doação; e formação de estoque pela agricultura familiar - CPR-Estoque. A Lei 12.512, de 14 de outubro de 2011, no seu artigo 24, Art. 24, instituiu os Conselhos de Segurança Alimentar e Nutricional - CONSEA como as instâncias de controle e participação social do PAA, ressalvando que, na hipótese de inexistência deste conselho na esfera administrativa local, fosse indicada outra instância de controle social, responsável pelo acompanhamento de sua execução (BRASIL-MDS, 2014). Ou seja, poderia não se ter CONSEA, mas deveria se ter sempre controle social.

A CPR-Doação é uma política pública de compra de alimentos que realiza a distribuição deles às instituições, entidades públicas ou comunidades que sofrem com a insegurança alimentar e nutricional. Sua funcionalidade é validada pela Lei $\mathrm{n}^{\mathrm{o}} 11.346$, de 15 de setembro de 2006,

\footnotetext{
“(...) que estabelece as definições, princípios, diretrizes, objetivos e composição do Sistema Nacional de Segurança Alimentar e Nutricional SISAN, por meio do qual o poder público, com a participação da sociedade civil organizada, formulará e implementará políticas, planos, programas e ações com vistas em assegurar o direito humano à alimentação adequada" (BRASIL, 2006, p. 1).
}

Por intermédio do Estado, através de programas como o PAA, essa troca mercantil-social é realizada mediante uma rede integrada de cooperação entre parceiros do governo e a sociedade civil. Segundo Oliveira (2020), a construção de políticas públicas socioassistenciais em alimentação conduziu à criação do Programa Fome Zero-FMZ, abrangendo os seguintes eixos: acesso aos alimentos; fortalecimento da agricultura familiar; geração de renda; articulação, mobilização e controle social. Segundo Serenini (2015), a agricultura familiar é responsável pela produção de $70 \%$ dos alimentos básicos consumidos pelos brasileiros, obtendo notoriedade no desenvolvimento regional, contribuindo para a diminuição do êxodo rural e distribuindo a maioria da sua produção para o mercado local e regional. A agricultura 
familiar tem cumprido com seu papel na produção de alimentos, assim como, tem contribuído para a garantia da segurança alimentar e nutricional da população brasileira, sobretudo da classe que vive em situação de vulnerabilidade socioeconômica e necessitam de políticas públicas socioassistenciais em alimentação.

É direito de todo ser humano ter uma alimentação adequada às suas necessidades, que atende às suas demandas nutricionais, que seja saudável, do ponto de vista da saúde, mas também que respeite a cultura alimentar, que seja produzida por meios sustentáveis economicamente, socialmente e ambientalmente falando. Também é necessário que todo ser humano tenha acesso e disponibilidade permanente de alimentos de qualidades, sem colocar em questionamento ou ameaça os outros direitos de acesso a uma vida digna. Portanto, é fundamental que haja um exercício de controle social sobre os programas socioassistenciais em alimentação e sobre as políticas públicas como um todo para que de fato ocorra o cumprimento da função social junto àqueles que essas políticas devem servir.

\section{Segurança Alimentar E nUtricional em feira de SANTANa}

A cidade possui uma seção do Movimento Nacional da População de Rua - MPRua. Este é o chamado núcleo de Feira de Santana, que representa uma população que, tendo aumentado nos últimos anos, aproxima-se das 400 pessoas. O MPRua desenvolve sua atividade em base a três pilares: convivência na rua, controle social e produção científica e o Grupo mantém vínculo regular e convergência o terceiro deles, na tentativa de contribuir à defesa dos direitos conculcados e à eficácia das políticas públicas.

Convergente com o anterior, o MPRua constata permanentemente as insuficiências dos órgãos e equipamentos públicos que existem para sanar as vulnerabilidades da população. No tocante à alimentação, o MPRua é categórico em afirmar que o poder público se omite diante da população de menor renda, em particular a que está em situação de rua, que vive com diversas carências de atendimento, entre outras o acesso às refeições necessárias, todos os dias. O Restaurante Popular de Feira de Santana, um programa federal situado no Centro de Abastecimento - CEASA, pensado para fornecer somente o almoço, funciona apenas de segunda a sexta-feira e exige $\mathrm{R} \$ 2$, o que as pessoas em situação de rua não têm, rotineiramente. A alternativa existente, o Centro Social Monsenhor Jessé, é ligado à Igreja Católica e depende de doações, suscetíveis de descontinuidades.

\subsection{O grupo PET Engenharias no Controle social do PAA}

O Conselho Municipal de Segurança Alimentar - CONSEA de Feira de Santana, foi criado em 2004, desativado por uma década e recomposto em 2014, como resposta à nova condição para a administração municipal preencher, para receber recursos federais. Durante o biênio 2014-2016, um membro do PET Engenharias esteve representante do ensino superior no Conselho, mas a Prefeitura Municipal mudou as regras de composição e, a partir daí, alijou 
a UEFS do assento nesse Conselho. Os representantes do Grupo foram transformados compulsoriamente em ouvintes nos dois mandatos seguintes, sem direito a convocatória.

No caso do Programa de Aquisição de Alimentos - PAA em particular, política pública federal que se identifica com o lema "renda para quem produz, comida para quem precisa", o Grupo vinha tendo dificuldades para obter acesso às informações oficiais do Conselho e passou a fazer visitas, atividades de extensão com os produtores familiares de sete locais nos distritos do Norte do Município. O Grupo condensou dados obtidos tanto em bases oficiais e através de consulta popular, dialogando com agricultores e agricultoras familiares que estão cadastrados no programa. Além disso, foram realizadas tentativas de participação no Conselho Municipal e acompanhamento através de outros grupos, no entanto, não obtivemos sucesso. Em 07 das entrevistas, o Grupo percebeu que as aquisições de alimentos eram realizadas intempestivamente. Também foi observado que tanto o cadastramento dos produtores (570) quanto a distribuição dos alimentos (112 entidades) eram feitos sem critérios estabelecidos abertamente, com vários casos de agricultores que não eram mais possuidores de tal terreno ou entidades que não mais existiam. Ainda, a prefeitura negligenciava as mazelas estruturais pelas quais passa a agricultura familiar no Município, como a falta crônica d'água e propriedades de tamanho inferior ao necessário para a atividade agrícola.

A partir destes contatos e verificação de informações, foi possível chegar às seguintes constatações: 1) as aquisições de alimentos eram realizadas intempestivamente, impedindo o planejamento dos fornecedores e lesionando o propósito da sustentação econômica dos agricultores; 2) o cadastramento era feito com critérios proselitistas, condicionando a permanência nele a um comportamento de troca de favores; 3) o gestor não responde com propostas à falta crônica d'água; 4) as propriedades são de tamanho inferior ao necessário para a atividade agrícola sustentada e não proporciona ATER (Assessoria Técnica Rural); 5) o CONSEA atua apenas como necessidade formal local para receber benefícios federais e alija a participação de representantes legítimos; em soma 6) dificulta, praticamente impede, o controle social e conculca a eficácia das políticas públicas relacionadas com alimentação.

A construção do programa e as ações deliberadas no conselho devem partir das demandas de uma sociedade que apresenta traços marcantes da desigualdade social, especificidades alimentares e essas precisam ser pontuadas por essas figuras, os agricultores precisam ter autonomia de planejamento e decisão sobre a produção de alimentos, prazos e quantidades, sobretudo porque dependem dos fatores edafoclimáticos da região; as políticas públicas referentes a demanda hídrica regional devem ser construídas de acordo com as perspectivas dos povos que produzem e o CONSEA se apresenta como um importante instrumento que funciona não só como ouvidoria, mas como um espaço de disputa de interesses, construção coletiva e incorporação das demandas da maioria da população, maioria essa a quem o programa deve estar à serviço.

O envolvimento dos estudantes na atividade extensionista propicia, uma vez que o grupo segue acompanhando o programa, a oportunidade desses tomarem conhecimento das 
problemáticas presentes e da importância das políticas públicas, em específico o PAA, a partir do contato direto, dialógico e constante com a sociedade. A ação extensionista se apresenta como um espaço de formação cidadã e construção de conhecimento, além de contribuir para que os estudantes envolvidos reflitam sobre as origens e consequências da negação de direitos aos trabalhadores e se coloquem para repensar a sua formação e como essa pode ser um instrumento para dar respostas ao campo que busca realizar uma comunicação dialógica, a partir da perspectiva construtiva, democrática, emancipadora e libertadora, promovendo o resgate e o fortalecimento de direitos.

\section{CONSIDERAÇÕES FINAIS}

Embora dois terços dos componentes do CONSEA devam ser oriundos da sociedade civil, há uma resistência por parte da Prefeitura Municipal no que diz respeito à participação democrática e ativa de representantes na composição e reuniões do CONSEA. Por vezes, percebe-se que os conselhos não estão imunes aos conflitos de interesses, cooptação e disputas da direção da política social articuladas a projetos socioassistenciais. No conselho, alguns representantes da sociedade civil colocam-se como meros ouvintes das discussões e a prefeitura se utiliza da presença deles como uma forma de assegurar perante a sociedade que a construção do planejamento e efetivação do programa está sendo democrática, participativa, eficaz e que possui um cunho popular, determinado segundo as necessidades dos beneficiários do programa, sem que isso se verifique nos fatos.

É perceptível que as constatações diagnosticadas pelo grupo através do diálogo com beneficiários e não-beneficiários do programa decorrem do enjeitamento da participação popular no CONSEA e da não efetivação do controle social sobre os recursos públicos socioassistenciais em alimentação. É evidente a questão da falta de transparência das ações relacionadas à aplicação do programa no município e é sabido que algumas constatações feitas estão vinculadas a pautas que não são recentes. A partir disso, surge o seguinte questionamento: Como a ação extensionista pelas engenharias possibilita a efetivação do controle social sobre essa política socioassistencial em alimentação?

As constatações feitas pelo PET Engenharias deixa evidente que não existe controle social democrático e participativo, pois algumas das problemáticas existentes não são recentes, possuem caráter estrutural e, possivelmente, não existiriam se os beneficiários, fornecedores e consumidores, estivessem inseridos e atuando como protagonistas no CONSEA, desde formulação, no planejamento de projetos relacionados ao programa, cadastramentos dos beneficiários, acompanhamento, execução das atividades, até a definição dos recursos que serão destinados para que esses atendam aos interesses do coletivo. Problemáticas como a falta de água crônica e tamanho insuficiente das propriedades estão diretamente relacionadas à história do semiárido baiano, não surgiram em decorrência do programa e poderiam ser resolvidos através da construção ou efetivação de políticas públicas já existentes de incentivo ao fortalecimento da agricultura familiar através da política 
territorial para desenvolvimento rural da região, iniciativas essas que poderiam estar vinculadas à prefeitura municipal ou ao governo do Estado, promovendo também o cadastramento de novos núcleos familiares ao grupo de fornecedores do programa, como as famílias do território quilombola e do assentamento pela reforma agrária.

Cabe destacar a importância de uma ação extensionista que dialogue com os beneficiários, que busque entender as problemáticas enfrentadas referentes ao PAA e que busque, acima de tudo, contribuir na organização desses agricultores e das outras categorias que são beneficiadas através do programa, proporcionando espaços de articulação e conscientização da importância desse, do CONSEA e da participação popular ativa.

Em termos mais amplos, as metodologias utilizadas nas atividades de extensão contribuem também ao processo de comunicação e construção da consciência coletiva das necessidades de organização para que os seres envolvidos se articulem, pleiteiem a participação que lhes é de direito e sejam sujeitos de transformação da sua própria realidade. As ações extensionistas também se mostram fundamentais para a formação cidadã dos estudantes envolvidos, uma vez que os currículos dos cursos de engenharia, em sua maioria, possuem um caráter puramente técnico e não são voltados para o necessário debate de questões sociais e políticas como essa. É preciso tomar consciência da própria função diante da sociedade e os espaços de troca de saberes com a comunidade contribuem para o aprendizado e formação de profissionais que estejam aptos para o desenvolvimento dos seus atributos técnicos, mas que consigam compreender de forma sistêmica a realidade do meio e atuar conforme as demandas diagnosticadas, considerando aspectos culturais, sociais, políticos, econômicos e ambientais. A formação humanística também perpassa pelo conceito de universidade socialmente referenciada, a construção de ações extensionistas possibilita que os indivíduos se coloquem para repensar o projeto político-pedagógico da universidade.

\section{REFERÊNCIAS}

BRASIL - MDS. Manual Operativo do Programa de Aquisição de Alimentos. 174 p. 2014.

Disponível

em

http://www.mds.gov.br/webarquivos/publicacao/seguranca_alimentar/manualPAA.pdf.

Acesso em 02 fevereiro 2020.

BRASIL. Constituição (1988). Constituição da República Federativa do Brasil de 1988. CAPÍTULO III- DA EDUCAÇÃO, Art. 207. Disponível em: http://www.planalto.gov.br/ccivil 03/constituicao/constituicao.htm . Acesso em: 24 jul. 2020.

BRASIL. Lei. 11.346, de 15 de setembro de 2006. Institui o Código Civil. Diário Oficial da União: seção 1, Brasília, DF, ano 143, n. 179, p. 1, 18 de setembro de 2006.

CALVI, Kéttini Upp. O controle social nos conselhos de políticas e de direitos. Revista Emancipação, Ponta Grossa, v. 8 n. 1. p. 9-20, 2008.

FORPROEX. Política Nacional de Extensão Universitária. Manaus, 2012. Disponível em 


\title{
Evento On-line
}

https://proex.ufsc.br/files/2016/04/Pol\%C3\%ADtica-Nacional-de-Extens\%C3\%A3o-Universi $\mathrm{t} \% \mathrm{C} 3 \%$ A1ria-e-book.pdf. Acesso em 02 fevereiro 2020.

HOFLING, Eloisa de Mattos. Estado e Políticas (Públicas) Sociais. Cad. CEDES, Campinas, v.21. n. 55. p.30-41, nov. 2001. Disponível em: https://www.scielo.br/scielo.php?script=sci arttext\&pidS0101-32622001000300003\&lng=pt \&tlng=pt . Acesso em: 27 jul. 2020

OLIVEIRA, Glaucia Maria da Silva. Análise da Atuação no Programa de Aquisição de Alimentos (PAA) no Fortalecimento da Agricultura Familiar em Feira de Santana. 2020. 64 f. Monografia (Graduação)- Universidade Estadual de Feira de Santana, Feira de Santana, 2020.

SERENINI, M. J.; MALYSZ, S. T. A importância da agricultura familiar na produção de alimentos. Curitiba: Cadernos PDE, 2015.

\section{EXTENCIONIST ACTIONS FOR SOCIAL CONTROL OF PUBLIC FOOD SOCIO ASSISTANCE FUNDS}

\begin{abstract}
In times of estimated Brazilian return to the FAO Hunger Map, this paper identifies the multidimensional nature of the matter. The authors show data analysis and findings of PET Engenharias (undergraduate Engineering Tutorial group) around the Food Acquisition Program - PAA Direct Purchase (that works with the motto "Income for those who produce, food for those in need") and assay the effectiveness of this public policy with federal resources. For this purpose, the Group participated in the Municipal Food Security Council CONSEA of the city, accessed registrations of both producers (570 entities) and recipients of food (112 entities) and made visits to family producers from seven locations, in the County Northern districts. The Group members were turned into listeners in the Council only: they made findings such as the next five. 1) Food purchases made in a timely manner, hindering suppliers planning and undermining the purpose of economic support for farmers. 2) Registration done with proselytizing criteria, conditioning the permanence to a favours' exchange behaviour. 3) County Mayor not act to solve the water problem. 4) Land properties are of smaller size than necessary for sustained agricultural activity. 5) CONSEA acts only as a formal local need to receive federal benefits and hosts the participation of legitimate representatives. Summarizing, the local PAA fulfilment hinders, practically prevents, social control and blocks the effectiveness of public policies related to population nourishment.
\end{abstract}

Keywords: Public policy. Food and nutritional sovereignty. Municipal CONSEA. Food Acquisition Program - PAA Direct Purchase. 